\title{
THE CHINESE INTERMEDIARIES AND THE CROSS-CULTURAL MIGRATION OF A JAPANESE ADULT VIDEO ACTRESS
}

\author{
MEI ZHANG \\ InSTITUTE OF JAPANESE STUDIES, CHINESE ACADEMY \\ OF SOCIAL SCIENCES
}

\begin{abstract}
Ayako, a Japanese adult video (AV) actress, has achieved amazing popularity in mainland China since 2010. This paper investigates how the two Chinese agencies re-produce and re-package Ayako as a cultural product in the Chinese context, based on the data obtained by participant observation. It aims to reconsider current theories on the cross-cultural migration of cultural products by revealing the roles of local intermediaries. The findings reveal that the two Chinese agencies played a significant role in the "transformation" of the cultural product in China, even though their operations are usually invisible to outsiders. The two Chinese agencies not only attempt to remove Ayako's previous image as an AV actress, but also assign abundant new meanings to her to make her acceptable in China. The findings also suggest that power relations between different cultural groups "inside" the intermediaries have a great impact on the transformation of the cultural product.
\end{abstract}

Keywords: cross-cultural migration, cultural products, local intermediary, Japanese adult video, Chinese media

\section{Introduction}

Ayako, ${ }^{1}$ a Japanese adult video (AV) actress, has become highly visible in the Chinese media, especially since 2010 when Chinese Internet users

\footnotetext{
1 The name Ayako is a pseudonym. All the names of chief executives, employees and artists inside the two Chinese agencies, and the names of the two Chinese agencies, Orchid and Sakura, are also pseudonyms.
} 
discovered her Twitter account. Although Twitter cannot actually be accessed directly from mainland China, many Chinese Internet users break the "Great Firewall of China", which cuts off Internet access to undesirable foreign websites, to follow Ayako's Twitter. As a result, Ayako's Twitter followers increased from 2,000 to about 20,000 within a day. She then opened an official account on Weibo, China's Twitter, in 2011. Ayako's Weibo followers exceeded 1.6 million in 2015. Almost everything that she said or did attracted huge attention among Chinese Internet media outlets. Reports on her have frequently appeared not only in influential commercial online news portals, but also in various newspapers.

Considering the context in which pornography is prohibited by Chinese government, the high popularity of this Japanese AV actress in China is an intriguing phenomenon. This paper is an anthropological study of how her two Chinese agencies re-produce and re-package Ayako as a cultural product. Its main concern has been to reveal the roles of intermediaries in the process of the articulation between foreign products and local society and to address, if not challenge, current theories on the cross-cultural migration of cultural goods. It argues that the significance of intermediaries between foreign products and local consumers should not be ignored. It also reveals that power relations between the chief executives of the two intermediaries with different cultural backgrounds have a great impact on the transformation of Ayako's image in China.

This paper starts with a review of literature on cross-cultural migration of cultural products to delineate the main debate of two dominant paradigms in this field. Based on the data obtained by participant observation, it then focuses on how the Chinese chief executive seeks to reproduce Ayako as a cultural product by assigning new meanings to her. It will also show that the Chinese chief executive's reproducing strategies have become prevalent owing to the arrangements of space and human resources inside the two agencies.

\section{Debate on the Migration of Cultural Products}

The close relationship between culture and products has been widely recognized by many scholars. Douglas and Isherwood point out that products are needed for "making visible and stable the categories of culture" (1979:59) and products "in their assemblage present a set of meanings" (Douglas and Isherwood 1979:5). Following Williams' definition of culture as "a description of a particular way of life which expresses certain meanings and values" (1961:57), Du Gay et al analyzed the production and consumption of the Walkman, an electronic product 
from Sony, and state that "the bringing of the object into meaning is what constitutes it as a cultural artifact" (1997:10).

However, the migration of cultural products can be more easily observed in recent decades because so many products are produced in one country and consumed in another. Do the products still substantiate the culture of their origin after they have crossed cultural borders? In analyzing the cultural effects of the migration of cultural products, Howes summed up two dominant paradigms in academia, the global homogenization paradigm and the creolization paradigm (1996:3-5).

The global homogenization paradigm highlighted the concern that cultural differences in the world have been gradually reduced because uniform mass-products have replaced local products throughout the world (Howes 1996:3). This paradigm is associated with American cultural hegemony, and thus is labeled as McDonaldization and cultural imperialism (Ritzer 2008[2004]; Tomlinson 1999). In contrast to the global homogenization paradigm, the creolization paradigm emphasizes the process of recontextualization through which foreign goods are assigned new meanings and inserted into particular social relationships (Howes 1996:5). It pays more attention to the creativity of local society and local consumers, and stresses that the intentions of global producers are not guaranteed to be recognized or respected by local consumers (Howes 1996:5-6).

These two major paradigms emphasize either the unbeatable dominance of global force or the creativity of local people. The theoretical origins of the two paradigms are different. Some scholars who support the homogenization paradigm are inspired by the Frankfurt School, popular in the 1930s and 1940s, which emphasizes the dominant functions of media texts (Cochran 2006: 2). The creolization paradigm is influenced by the Birmingham Centre for Contemporary Cultural Studies (BCCCS) in the UK, and anthropology as a discipline (Featherstone and Lash 1995:3)

The concept of cultural imperialism, which is concerned with the homogenizing effect of cultural products in the world, emerged in the 1960s, and intensified in the 1980s against the backdrop of the popularity of American products, such as Hollywood movies, popular culture, fast food, jeans, and so on. Schiller's 1969 book, Mass Communication and American Empire, launched the academic discussion of cultural imperialism. He showed strong concern for the fact that Western countries, led by America, took advantage of capital and technology to export Western technology and equipment and forced developing countries to accept their television programs (Schiller 1969:110-113). He stated that American commercial communication corporations played a leading role 
in the circulation of American values and ideology to every corner of the world (Schiller 1969:92).

Hamelink (1983) followed Schiller's view, claiming that the process of cultural homogenization, caused by the spread of global capitalism, has become unprecedented in the world since the 1950s. He described the process as a "destructive" one because it threatened the cultural autonomy of other countries and the diversity of cultural systems (Hamelink 1983:4). He noted the dumping of Western commodities, such as Coca-Cola and jeans, onto developing countries with complete disregard for local people's reactions to these foreign goods.

In contrast, some anthropological studies on the reception of global products by local consumers question the concepts of cultural imperialism and homogenization. Liebes and Katz (1994) examined how television viewers in Israel, Japan and the U.S., reacted differently to the popular television series Dallas, an American television drama which was popular in almost 90 countries in the 1980s. Its popularity was thus easily labeled as cultural imperialism. However, Liebes and Katz (1994) showed not only that viewers in different countries, but also viewers within Israel with different ethnic backgrounds, read Dallas differently. They argued that the critical ability and the creativity of the audience in various social contexts should be fully recognized (Liebes and Katz 1994).

In the same vein, Watson's (1997) research on McDonald's also questioned the global homogenization paradigm. In order to examine whether McDonald's presages a homogeneous, global culture, Watson (1997) analyzed consumers' responses to McDonald's in five East Asian cities: Hong Kong, Beijing, Taipei, Seoul, and Tokyo. This research shows that East Asian consumers have transformed Macdonald's into a local institution. In contrast to their orientation as fast food outlets, Macdonald's restaurants have become leisure centers in Beijing, Seoul, and Taipei, and youth clubs in Hong Kong, where middle school students study and chat for hours (Watson 1997).

Both Liebes and Katz (1994) and Watson (1997) conducted fieldwork to examine the creative responses of local consumers to global products. However, they seldom considered the impact of other local groups, such as the local branches of McDonald's, local business partners, local media, and so on, on the acceptance of foreign cultural products in the local society.

As such, the debate of the global homogenization paradigm and the creolization paradigm lingered in academia in the 1990s (Pieterse 1995; Robertson 1995; Appadurai 1996; Hannerz 1996). However, some scholars have been dissatisfied with the two paradigms. Goldstein-Gidoni 
points that both these two paradigms are unable to fully explicate the complexities of the process of cross-cultural migration (2001:68). Cochran (2006) also questions the two different paradigms by pointing out that they provide a conflicting picture of the migration of cultural products. $\mathrm{He}$ states that Western corporations did not touch individual consumers directly in a non-Western local culture, as the two paradigms assume. Instead, not only Western corporations and local consumers, but also brokers in between, were important agents of Chinese consumer culture in the nineteenth and early twentieth centuries (Cochran 2006).

Although the analyses of intermediaries are still very limited, their significant role in propelling transnational corporations to success has begun to be recognized. Adopting the research method of in-depth interview, Nakano's (2009) research reveals that the Hong Kong distributor, William Mong, as the sole agent of National (later known as "Panasonic") brand of rice cookers in Hong Kong, involved himself in the process of production and made novel contributions to National's re-designing of their rice cookers to ensure that the products would cater to Hong Kong people's preferred cooking styles (Nakano 2009). As one of representative works on the dissemination of Japanese culture, Wong and Yau's (2014) research also sheds light on the crucial role of intermediaries as a re-producer of foreign products. Through detailed analysis of the Chinese subtitles, they examined how Taiwanese disk counterfeiters assigned new Chinese subtitles to original Japanese AVs, according to the sexual roles of men and women in Taiwan, to make Japanese AVs sexually appealing to local viewers (Wong and Yau 2014:67-95).

Nakano (2009) and Wong and Yau's (2014) studies urge us to pay more attention to the examination of the role of local intermediaries in the circulation of foreign cultural products. However, studies based on fieldwork "inside" the local intermediaries are still limited. Nakano (2009) and Wong and Yau's (2014) pointed out the local intermediaries' functions to "partially" modify the cultural meanings of products to cater to the needs of local consumers. However, my research shows that the local intermediaries seek to dramatically "transform" the meanings of foreign products. Their studies also have their limitations in the sense that they treated the Hong Kong intermediary as a coherent monolith. In other words, they did not explore how the contradictions "inside" the local intermediaries had had an impact on the changes of the meanings of foreign products.

This paper aims to contribute to the ongoing debate between the global homogenization paradigm and the creolization paradigm by revealing the roles of intermediaries and the contradictions "inside" the local intermediaries. 
In so doing, it helps enhance our understanding of the "mediation" between global force and local society, as Wong and Yau (2014) suggest. This study shows that intermediaries like Orchid and Sakura play a significant role in the "transformation" of the global products in the local context, even though their operations are usually invisible to outsiders. The intermediaries attempt to remove Ayako's previous image as an AV actress and assign new meanings to make her image acceptable in China, as her re-producers. This study demonstrates that it is inaccurate to assume that all the meanings of global products in their local contexts are created by foreign corporations or local consumers. Meanwhile, the intermediaries should not be treated as a harmonious monolith.

\section{Methodology}

The ethnographic method has become a powerful tool for anthropologists to make great contributions to the field of business (Tian 2010; Jordan 2010). Tian has pointed out that "by participant observation business anthropologists can reveal informal social structures and patterns of behavior that exist as well as tensions that might not be obvious at first glance" (2010: 84). As a "culturally sensitive qualitative method", the ethnographic method is very effective in investigating the organizations "where ethnic diversity exists" (Walle 2016:44).

In order to investigate the impact of intermediaries' repositioning on the evolution of the Japanese AV actress's meanings in Chinese context, I conducted participant observation in Orchid, one of Ayako's Chinese agencies located in Beijing, from August 2012 to November 2013. I received permission from the chief executive of Orchid to work unpaid in their Promotions Department. My routine work was to write promotional news or materials for Ayako and other artists in Orchid. Because I can speak both Japanese and Chinese fluently, I also interpreted for Ayako when she needed an interpreter for interviews or commercial activities.

For most Chinese audiences, Ayako's two Chinese agencies are invisible, despite their central role in promoting her celebrity status. Scholars in media studies also have pointed out that it is hard to grasp the information about the production of celebrity, partly because the celebrity industries deliberately "mask their activities" in order to "naturalize their professional practices" (Turner 2004:41). In other words, the celebrity industries try hard to make the public perceive the emergence of a celebrity as a natural thing, mostly due to the celebrity's own talents or gloss, rather than the production of celebrity industries. Therefore, anthropological field work in the agencies of the celebrity has become the 
most efficient research method for revealing the way in which the Japanese AV actress has been assigned new meanings as a cultural product by her Chinese agencies. It helps us to investigate the impact of "informal social structures" and the "tensions" (Tian 2010:84) inside the two agencies on the meanings of the foreign product.

\section{The Establishment of the Two Agencies}

Before the establishment of the two agencies, Orchid and Sakura, Ayako was a celebrated Japanese tantai (it literally means single body) ${ }^{2}$ AV actress. Ayako's fame and tremendous fan base are her two agencies' advantages. As is common with other tantai AV actresses, Ayako was picked out by a talent scout on a busy street of Tokyo because of her good looks. She made her debut in 2002, and did not stop AV acting until 2011. In total, she released about 80 AVs during this long period. When Ayako achieved popularity in Japan as an AV actress, her AVs migrated to China via the Internet in the 2000s. Through downloading her videos free from the Internet, many Chinese Internet users have become familiar with Ayako's name and body, which was well-known for the contrast between her cute childish face and huge breasts.

The event through which Ayako attracted intensive attention in Chinese society was the discovery of her Twitter account. Soon after she opened it in 2010, several devoted Chinese fans discovered it and spread the information on Twitter and other Chinese websites. Owing to the efforts of some Chinese Internet users to circulate her account, her Twitter followers increased from 2,000 to 20,000 within one day. This event was intensively covered by the Chinese media. Observing the popularity of Ayako among Chinese Internet users, Ushida, a Japanese man working in Beijing, hit upon the idea of establishing a new company to manage Ayako in China. Lacking experience of producing celebrities, he sought the help of Yang, a Chinese man who owned a recording company and had abundant cross-cultural and domestic star-making experience. Then the two Chinese agencies, Orchid and Sakura, were founded respectively in April, 2011 and November 2011.

Sakura is a very small company consisting of only two staff including Ushida. By contrast, Orchid is a company of around 20 people, responsible

\footnotetext{
2 The tantai is one category of Japanese AV actresses. Tantai actresses are those who have pretty faces and attractive bodies - key characteristics for performing in leading roles in AVs (Nakamura 2012:34). They have more opportunities for promotion and media coverage than other types of AV actresses.
} 
for the production of Ayako and other artists' music, taking promotional pictures for albums, making music videos and the promotion of artists' songs and movies. In other words, the biggest difference between Sakura and Orchid was that Sakura was established exclusively for Ayako, while Orchid was established to promote both Ayako and other artists. There were about ten singers in Orchid when it was founded, although some of them later left. It should be mentioned that neither of these companies is registered as a branch or subsidiary of a Japanese agency. The independence that the two agencies enjoyed allowed for Ayako's image to be transformed to a great extent in a Chinese context, according to the two local agencies' strategies.

Ayako's previous status as a pornographic star is risky in China because Chinese legislation clearly stipulates a ban on manufacturing, trafficking in, and disseminating pornographic articles. ${ }^{3}$ Ayako was asked to stop acting in new AVs by the two Chinese agencies in 2011. Meanwhile, in order to transform Ayako into an acceptable product in the Chinese market, the two agencies need to encode Ayako with new meanings. However, Ayako means different things for the two chief executives, Yang and Ushida, in the two companies. Their different perceptions of Ayako result in the different meanings and forms of Ayako as a product. In order to achieve their own perceptions and interests, they also have power struggles and conflicts.

\section{Ayako as a Symbol of Commercial Value}

For Ushida, the Japanese chief executive of Sakura, Ayako is a symbol of commercial value. Turner has pointed out that celebrity "is a financial asset to those who stand to gain from their commercialization-networks, record companies, producers, agents, managers and finally the celebrities themselves" (2004:35). It is particularly true for Ushida because Sakura was exclusively established for Ayako. As the sole Japanese staff in the two agencies, Ushida is responsible for reporting Ayako's activities in China to her Japanese agency, and then delivering the Japanese agency's opinions back to the two Chinese agencies. That is to say, he is authorized by the Japanese agency to monitor the operations of Orchid. Therefore, Ushida pays more attention to the rise or fall of Ayako's fame in China. He estimates Ayako's commercial value through the ranking of famous people

\footnotetext{
${ }^{3}$ The Criminal Law of the People's Republic of China, amended by the Fifth Session of the Eighth National People's Congress in 1997, is the primary legal provision concerning pornography in China.
} 
in Baidu.com. When Ayako's ranking falls, he feels anxious and urges Yang and other managers to hold meetings to discuss solutions.

Ushida has very high expectations of Ayako's commercial value. However, he is not as familiar with the actual practices of Chinese celebrity industries as are the Chinese staff in Orchid. When cooperation offers came from the media, the different expectations of staff in Orchid and Ushida became very obvious. For staff in Orchid's Promotions Department, it has become a commonplace that it is much cheaper for a celebrity to attend events held by the media than commercial activities held by other production companies, because these events are usually reported extensively by the media. The celebrity needs to show his or her gratitude to the media for the publicity, and tries to maintain cooperative relationships with them. However, Ushida did not think so, and requested a high price for even attending media events. As a result, some media did not invite Ayako the second year. It is not rare for staff in the Promotions Department to complain: "I was so surprised that they charged such a high price for a media event. This year they [the media] did not contact me again." This case indicates that Ushida's strategy differed from the staff in Orchid. Ushida assumed Orchid should charge a high price no matter what kind of event Ayako is attending. This incident also reveals that staff in Orchid are more familiar with the conventional practices of local media than Ushida, and exposes one of Ushida's weaknesses.

Although he does not basically directly intervene in the activities of the Promotions Department, Ushida sometimes complained to me furtively that the Promotions Department's work was too boring. "They only arrange routine interviews. The interviews are not interesting at all. Every time, all the interview questions are in the same key." He insists that Ayako's media profile should be as an interesting and humorous star. When directing the way in which Ayako answers interview questions, he always asks Ayako to answer in a humorous way. Ushida's insistence on humor has inscribed Ayako with a humorous public personality. We can see that Ayako's on camera personality is not a personal choice made by Ayako herself, but is a decision made in consultation with the directors behind the camera. These people have considerable power in directing the way that Ayako presents herself.

The reason why he insisted on the principle that Ayako should be an "interesting" product lies in his assumption that Chinese Internet users love to chat with humorous people because they have a lot of pressure and want to release it. He regards the telling of jokes as an effective way to communicate with Chinese Internet users, and suggests that Ayako flirt with Internet users. He thinks that as a previous AV actress, Ayako should 
not be priggish. Telling jokes can make Ayako look more easy-going and attractive.

Sometimes Ushida also has creative ideas about Ayako's image. For example, taking into account the fact that Ayako's name has become sensitive, he even considered promoting Ayako under a different name and as another persona in another platform of social media other than Weibo. Thus there would be two Ayakos, with different images on different social media platforms. Although this idea was once conveyed to the Promotions Department through Ayako's assistant, it was difficult for them to put it into practice because Yang actually controls this department to realize his own ideas. This incident revealed that Ushida also wanted to become a producer of Ayako and someone who contributes to Ayako's representation in China. However, without the cooperation of the Promotions Department his ideas struggle to be realized.

Overall, Ushida's biggest concern is Ayako's commercial value. Paying attention to Ayako's commercial value motivates him to constantly monitor the promotional effect of the Promotions Department of Orchid. He tends to think the work of the Promotions Department is "boring", and insists that Ayako should be humorous and interesting. Since the Promotions Department does not execute his ideas, instead he actively creates a humorous personality in Ayako through directing her responses in interviews and on Weibo. This is where Ayako's media image as a humorous girl originates.

\section{Ayako as Yang's Masterpiece}

In contrast to Ushida, who pays more attention to Ayako's commercial value, Yang, the Chinese chief executive of Orchid, views Ayako as his masterpiece and a means of self-actualization. Although it is undeniable that Yang's aim is also to obtain profits from Ayako's commercialization, Yang usually hides this desire, but appears as a dream-maker who explains the dream that he created for Ayako not only to the audience, but also to employees in the companies. The following part will analyze the kind of cultural meanings that Yang intends to assign to Ayako and why, taking his personal working experience and the Chinese media and market into account.

Yang is a creative designer with inspiring ideas about how to rebuild Ayako's image in China. He repositions Ayako and interprets Ayako's significance by listing her one of the four important female stars in the history of non-governmental cultural exchanges between China and Japan. In an interview that I conducted with him in October 2013, he 
complacently described his vision.

In producing Ayako, I have my own perspectives. In terms of the China-Japan relationship, I think four females have made remarkable contributions: Li Xianglan, Yamaguchi Momoe, Sakai Noriko and Ayako. They are so famous that they have completely penetrated Chinese society... As to the first and the second females, I was only a spectator, not a participant. As to Sakai Noriko, fortunately I participated in the project. But that was only a partial participation because I could not control the whole project. As to Ayako, who is as famous as the other three in China, I can participate in the process. I can control what she will do and in which direction she will go. That is what I want. (Yang, interview [October 30, 2013])

These paragraphs describe his approach to promoting Ayako in China. Yang laughed loudly in the interview, and very often with pride because it seems that he regards Ayako as one of the masterpieces in his career as a professional star-maker. Ayako has been reinterpreted in the context of non-governmental cultural exchanges between China and Japan, being elevated to the same status with other three female stars who gained popularity in mainland China in the 1930-40s, the 1980s, and the 1990s, respectively. Thus Ayako has been repositioned as a key figure who contributes to cultural exchanges between China and Japan in contemporary China through her art. There are two reasons why Yang repositioned Ayako as one of four key figures in the history of China-Japan cultural exchanges.

\section{Yang's Ambition to Make a Name in History}

The first main reason is Yang's ambition to make a name in history through the creation of Ayako as a figure with historical significance. There are different levels in his personal involvement in the cases of the four female Japanese stars. He understood the popularity of Li through books, and saw Yamaguchi's farewell concert in Japan with his own eyes as one of her Chinese fans. He could not be involved in the shaping of fame in the first two cases. However, Yang had the precious opportunity of being involved in the production and promotion of Sakai Noriko's Chinese album in the 1990s when he worked for the Japanese recording company called MUSIC. ${ }^{4}$ It is almost impossible to understand why he repositions Ayako this way without the analysis of his personal experiences studying

${ }^{4}$ This is not the recording company's real name. 
and working in Japan, especially the experiences of his encounter with Sakai Noriko.

Yang was born in Beijing in the early 1960s, and entered university in Beijing to study architecture in 1979, but dropped out because he was not interested in his major. ${ }^{5}$ He was curious about the world and wanted to broaden his horizons. In 1985, he went to Japan with the dream of becoming a singer. After learning Japanese for two years, he entered Hosei University, a well-known Japanese university, and did some part-time work to pay for his tuition. He decided to join a record company after graduation because he read the biography of the founder of MUSIC, by this time a well-known Japanese recording company. Inspired by the founder's story, he realized that he was better suited to the role of the boss who helps music lovers to achieve their dreams rather than becoming a singer himself.

In his third year at university, Yang started working in MUSIC, which at that time had more than 1,000 employees and many different departments. As a recording company, its core department was the Production and Promotions Department, which was responsible for producing albums and promoting artists. This department was located on the 8th floor of the company building, with only about 50 people working there. Yang dreamed of owning his own recording company, and so he wanted to use his time at MUSIC to learn how to produce albums and promote artists. However, at the beginning he worked in a department on the 4th floor with no chance to talk with the artistes or staff in the Production and Promotions Department. He jealously observed staff on the 8th floor going in and out with fashionable clothes while all the employees in other departments were asked to wear formal suits.

Two years later, the overnight popularity in mainland China of Sakai Noriko, a Japanese singer and actress, provided him with a precious opportunity to transfer from the 4th to the 8th floor. Sakai suddenly became extremely popular in China because of a 1993 Panasonic TV commercial featuring her. MUSIC decided to release a Chinese album for her because they held her recording contract. The Production and Promotions Department needed a person who understood Chinese and was informed of Yang's existence. Through a complex process, Yang was finally transferred to the core department on the 8th floor, excited that he could now work with staff wearing fashionable clothing in the Production

\footnotetext{
5 The discussion of Yang's previous experience is based on an interview conducted with Yang by the author in September 2013, and an interview conducted with Yang by Dr. H.W. Wong, and the author in October 2013.
} 
and Promotions Department.

Since he was the only Chinese, and the only foreigner, in MUSIC, Yang was given responsibility for market research, production, and the promotion of Sakai's Chinese album. First, he was required to do some market research about Sakai's popularity in China and find a local distribution company for Sakai's Chinese album. The second thing that Yang was asked to do was to help record Sakai's Chinese songs. In Yang's words, he suddenly went from being a nobody to being a producer because he was the only one in MUSIC who knew Chinese. He translated, or actually rewrote, the lyrics of Japanese songs into Chinese, and taught Sakai how to pronounce Chinese lyrics one word at a time. Third, after Sakai's Chinese album named Weixiao (Smile) was released in 1994, the Chinese side required that Sakai visit China for promotional events. Naturally, Yang became Sakai's guide and took charge of the press conference during Sakai's Chinese tour. In other words, Yang got to participate in the entire process of making Sakai's Chinese album, including market research, production, and promotion.

Two points emerge from this story. First, Sakai's case provides him with the experience of promoting Japanese female stars in China, and Sakai's case is very similar to Ayako's. Both women had been popular in Japan before they became well-known in China. Both of them became extremely popular in China almost by accident. Sakai's popularity came from Panasonic television commercials in China, and Ayako's came from the discovery of her Twitter account. Through Sakai's example, Yang had observed the amazing enthusiasm of Chinese audiences for a cute Japanese actress and had understood Ayako's huge commercial value. The experiences of producing a Chinese album for Sakai, teaching her Chinese, and promoting Sakai then provided Yang with a model for presenting Ayako to the Chinese market.

Second, and more importantly, we can see that Sakai's case provided him with a chance to participate in the process of star making. Before that, he had had no opportunity to come into contact with the core business of celebrity production even though he worked in the famous Japanese recording company. It was Sakai's overnight popularity that changed Yang's fate and enabled him to enter the recording industry. Later, he finally realized his dream of becoming the boss of a recording company after he came back to China from Japan. A famous star can make him become a person who can make a name in history. It is understandable that he cherished the chance to reproduce Ayako in China because it was another historical moment in which he could produce an epoch-making product. Unlike Sakai's case, in which he was merely an employee of 
MUSIC, in Ayako's case he was the boss of his own company. He expected that he could achieve more than he had with Sakai. In his thinking, reproducing Ayako as a historical figure would enable him to win historical significance for himself as well. His ambition to create history based on his experience in Sakai's case is one important reason why he linked Ayako with Sakai, and reinterpreted her from the perspective of the history of China-Japan's cultural exchanges. Through the reproduction of Ayako, his authority as a star-making expert in the industry has been reinforced. His expertise is attested to by the fact that he was invited to become the vice-president of another major entertainment company later.

\section{Abundant New Meanings of the Japanese AV Actress}

The second reason for Yang's repositioning lies in the consideration of the Chinese media and market. In other words, the abundant meanings and narrative lines of Ayako deriving from this repositioning are assumed to be suitable for media coverage and thus appealing to the market. The narrative line of Ayako that Yang prepared for the media is Ayako's "second dream", her transformation from an AV actress to a key figure contributing to cultural exchanges between China and Japan. Based on that, two layered meanings are included. The first one is the love of China and the advocacy of the friendship between China and Japan. The second one is gaining acting and singing skills through hard work. Thus Ayako acquired a rich set of meanings and positive connotations. These multiple meanings are assigned to Ayako through the association of Ayako with $\mathrm{Li}$ Xianglan, one of the four figures that Yang has mentioned.

Although Yang participated in the promotion of Sakai in China, he did not relate Ayako to Sakai directly, partly because Sakai was involved in a drug scandal in 2011. Instead, Li Xianglan became the metaphor that Yang used to assign new meanings to Ayako in the media. Although Japanese, Li was born in China's Liaoning province in 1920 and studied in a Chinese middle school in Beijing. She became a famous Japanese singer and film actress of the Machu Eiga Kyokai (Manchukuo Movie Association) in the 1930s and 40s. In movies, she often played the roles of Chinese women who fell in love with Japanese men, and thus functioned as a propaganda tool for constructing Manchukuo, although she did not realize it (Yamaguchi and Fujiwara 1991). She was believed to be a Chinese singer and actress and left many famous songs and movies. After Japan lost the Sino-Japanese war in 1945, Li was charged as a hanjian (traitor of China) and risked being executed. After she proved herself to be Japanese, she was sent to Japan along with other enemy aliens. In Japan, Li continued 
her acting career under the name of Yamaguchi Yoshiko, and later even became a senator. In her autobiography (Yamaguchi and Fujiwara 1991: 80), she calls China her "homeland", and Japan her "motherland", to express her love of China. As a senator, she opposed the prime minister's visit to the Yasukuni Shrine, saying "that will truly hurt the hearts of Chinese people" because she observed so much Chinese suffering in the war (Yamaguchi and Fujiwara 1991: 120). As such, Li is a legendary star with outstanding achievements in terms of singing and acting; meanwhile, she is a Japanese female who deeply loves China and advocates for peace and friendship between China and Japan.

Yang had been impressed by the story of Li and her songs when he went to a lecture by a professor in Shanghai. When given the chance to promote Ayako in China, he soon decided to link Ayako to Li (Yang, interview [October 30, 2013]). For example, Ayako's first short movie in China backed by her two agencies and directly supervised by Yang shows Yang's strong intention to bring Ayako into new meanings using $\mathrm{Li}$ as a metaphor. The storyline of the movie is relatively simple. Ayako plays a Japanese cosplayer who is upset after her partner leaves her. Inspired by a Chinese song sung by Li, the cosplayer comes to China and arrives in Shanghai, in the 1930s, in a dream. There she is encouraged by the old lady Li Xianglan and decides to pursue her dream bravely in China. Just as $\mathrm{Li}$ always does, Ayako wears multiple Chinese dresses in the movie. As $\mathrm{Li}$ speaks fluent Chinese, Ayako also acts in this movie speaking Chinese and singing the theme song in Chinese.

Through associating Ayako with Li, two layered meanings are given to Ayako by Yang. The first layer is Ayako as "an artist with true acting and singing skills". The fact that Li was not only an actress but an excellent singer is one important reason why Yang encouraged Ayako to become a singer. As an AV actress, it tends to be assumed by the Chinese audience that she does not have any acting skills, only having sex and appearing nude before the camera. Yang tries to change the audience's bias that Ayako only relies on a pretty face and sexy body to make a living, and to show that she will become a true artist with excellent acting and singing skills like Li, through singing Li's songs. However, unlike Li, Ayako was not born and brought up in China and did not have vocal training from childhood. She could neither speak Chinese, nor sing songs. She therefore needed to spend considerable time learning Chinese and singing. Hard work and resilience are necessary for her transformation.

Just as Jeffreys and Edwards have pointed out, one "feature of China's celebrity culture is the high value placed on attributes such as public propriety, group orientation, academic achievement, resilience and thrift" 
(2010:17). State-sponsored celebrities, such as military celebrities and "outstanding mothers" are good examples (Jeffreys and Edwards 2010). Ayako risked becoming a target of criticism because she was assumed to "poison young people". However, under Yang's narrative line, Ayako is positioned as someone who is trying to transform from an AV actress relying on her body and face alone, to becoming an artist with true performing and singing skills. Through this display of hard work Ayako can be presented as an exemplary model for young people. She presents her story of bravely pursuing a "second dream" in China as a way of instructing young people in correct behavior. Thus, based on Yang's vision, Ayako is elevated from a girl with "indecent" job to a model for young people pursuing their dreams to emulate.

The second layer is Ayako as a cultural bridge between China and Japan. Ayako's love of Chinese culture is demonstrated by important signs, such as Chinese dress, Chinese songs and Chinese lines, in her short movies and her mini concert invested by the two agencies. The Chinese media favor reporting the Chinese cultural symbols contained in Ayako's image, particularly her attempts to learn Chinese and calligraphy. Reports on her calligraphy and her involvement in Chinese culture not only routinely appear in entertainment channels of many news portals, but also show up in the "cultural" section or "domestic" section of print newspapers, instead of the entertainment section. The media favor stories about Ayako's involvement with Chinese culture, partly because these stories align with Chinese nationalism. Cong divides nationalism in China into several types (2009): a strengthening identification with the Chinese nation, which is often called "patriotism"; "a desire to vindicate the national interest and revive the national culture", which is "a response to globalization, especially the globalization penetrating into Chinese daily life" (Cong 2009: 832); and "an extreme and radical form" of nationalism showed by actions like boycotting other countries' products (Cong 2009:832). In Ayako's case, her image as a cultural icon caters to the second type of nationalism, the desire to carry traditional culture forward.

Yang Yingjie also points out that "state nationalism is embraced as a supplement ideology" (2003:2), and promoting traditional culture is a means to legitimate the rule of the $\mathrm{CCP}$ and to maintain national autonomy, unity and identity (2003: 17). Since the 1990s, a wave of calling for a return to Chinese traditions has begun to spread in the Chinese media, academia, and even in official behaviors. In 2001, CCTV (China Central Television) began to make a popular program Baijiang jiangtan (Lecture Room), inviting some experts and professors to explain Chinese classical literature works and Chinese history to the audience in plain language or 
by storytelling. In order to teach Chinese and spread Chinese culture, since 2004 Confucius Institutes have been established in South Korea, the United States, Sweden, Australia and other countries around the world (Chen 2009).

Ayako's efforts to learn Chinese, do calligraphy and act and sing in Chinese cater to the wave of reviving traditional Chinese culture across China promoted by the CCP and satisfying the nationalistic sentiments of Chinese Internet users. Her actions symbolize the idea that the value of China's traditional culture and Chinese language is acknowledged by Japanese people. That is the underlying reason why information about Ayako's involvement in Chinese culture was actively transformed into news by news portals and newspapers. That is to say, signifying Ayako as a fan of Chinese culture drew on Yang's considered calculation of the Chinese media demands at a time of rising cultural pride in China's traditions.

Just as Li Xianglan called for peace and friendship between China and Japan, a cultural bridge between China and Japan also implies the advocacy of the friendship between China and Japan. It is well known that there are many obstacles, historical problems, textbook problems and territorial disputes, which undermine the Sino-Japanese relationship. The career of Ayako in China as a Japanese star is subject to the vicissitudes of the broader Sino-Japanese relationship. Presenting Ayako as a cultural bridge between China and Japan helps Ayako stay above the complex and unstable Sino-Japanese relationship.

As such, through associating Ayako with existing Japanese star $\mathrm{Li}$ Xianglan, Yang has developed a distinctive set of meanings around Ayako. They can be divided into two layers: Ayako as an artist with true acting and singing skills, and Ayako as a cultural bridge between China and Japan. Every layer includes abundant meanings, such as hard work, a model of young people pursuing dreams, the recognition of Chinese culture by Japanese people, and the advocacy of the friendship between China and Japan. These new meanings guide Yang's instructions to employees about Ayako's promotion and publicity. Meanwhile, they are distinctive from previous meanings in Ayako's image, particularly poisoning young people, only relying on her body and looks, being legally and politically prohibited. In other words, Yang's repositioning strategy is an obvious image improvement: from selling her body to manifesting true performing ability, from indecent to being decent; from negative to positive; from politically prohibited to politically tolerated. Yang aims to replace previous meanings with new meanings and shrugs off her dominant image as a Japanese AV actress. As a result, there is a disjuncture between previous meanings in 
Ayako's image and new meanings that Yang assigns to her.

\section{Power Relations between Ushida and Yang}

Although he is authorized by Ayako's Japanese agency to monitor Ayako's promotion and marketing activities in China, Ushida lacks the power to control the entire process of Ayako's image reconstruction. In contrast, Yang's control over Ayako's production and promotion has been strengthened. As a result, Yang's repositioning has become widely shared and agreed upon within the two agencies. The power relations between Ushida and Yang are demonstrated by the arrangements of space and human resources.

\section{Spatial structure of the office}

Researchers have recognized that organizational power-relations are expressed in office layouts of the organizations (Dale and Burrell 2008; Hernes 2004; Kornberger and Clegg 2004). Spatial arrangements of these two companies provide evidences of the complex power relations between Ushida and Yang.

The offices of Ayako's two Chinese agencies are located in an art village near the famous 798 art district in the northeast area of Beijing. On one lot in this village are four three-floored red-brick buildings, two of which, Building A and Building B, are the offices of Sakura and Orchid. Building B comprises a huge professional recording studio and several small recording studios with recording equipment, and independent small rooms where performers compose. It is Building A where Ushida, Yang and the staff of the Promotions Department work.

The structure of the three floors of Building A is like a pyramid. The third floor is regarded as the core part where important people stay. Yang, the president of Orchid, has an independent large room with a separate toilet on the third floor. Near Yang's room are the Sakura offices housing Ushida and Lily, a Chinese girl who is Yang's most trusted person and represents Yang in all important matters dealing with Ayako. Ayako also stays in this office when she comes to China. The second floor consists of the Orchid vice-president's office, and the Financial Department. The spacious first floor which, is used by the staff of the Promotions Department, is less desirable than other places in the building because those who occupy it are assumed to be the lowest-ranked in the company.

By examining the spatial structure of the office building, it is evident that the staff of Sakura are ranked higher than the staff of Orchid. Almost 
every employee was aware of this because Ushida can be viewed as the representative of Ayako's Japanese agency. More importantly, Ayako and Ushida, both Japanese, were deliberately separated from most Chinese staff by being given a separate office on the third floor and a separate company, Sakura. In many companies, it is common to have an obvious cleavage between Japanese expatriates and the locals in Japanese subsidiaries abroad (Kidahashi 1987; March 1992; White and Trevor 1983; Wong 1999). Although Orchid and Sakura were registered as limited liability companies in China, different from Japanese subsidiaries abroad, there was also similar division between the Japanese and the locals in the same building.

One direct effect of the spatial separation is that the communication between Ushida and staff in Orchid is restricted. Staff can neither visit Ushida's office freely, nor speak to or greet Ushida. Although staff in Orchid often have lunch or have dinner together, Ushida is almost never invited to attend any Orchid parties. The reason is not that the staff in Orchid do not want to, but they have no chances to talk with him and invite him. As a result, Ushida's ideas about Ayako's image basically cannot penetrate Orchid or be conveyed to its staff. At the same time, staff in the Promotions Department do not understand Ushida's thoughts and decisions, especially when Ushida denies some arrangements for interviews or commercial activities initiated by the Promotions Department. Some staff in the Promotions Department are very hostile to Ushida and think of him as a "bad guy" who controls Ayako without understanding the actual situation of China. Under these circumstances, Ushida cannot intervene in, nor exercise control over, the everyday work of the Promotions Department instructed by Yang. He cannot get information about the industry or other companies who can do promotion through the communication with staff in the Promotions Department. The lack of communication leads to his inability to control the promotion process and it limits his access to industry information. Thus it becomes difficult for him to change promotion companies.

\section{Human resources arrangements}

Not only is Ushida's penetration into Orchid made almost impossible through spatial separation, but his power inside Sakura has also been weakened by personnel changes. There are only two staff, Ushida and Lily, in Sakura's office on the third floor. Originally, Ushida had a most trusted Chinese subordinate called Alan, who worked as Ayako's former assistant and manager in Sakura. Alan understood a little Japanese and played a 
significant role in the early period of the successful crafting of Ayako's Weibo persona. Ushida trusted him very much and believed in his ability to promote Ayako and negotiate business cooperation for Ayako. With Ushida's support, Alan had a close relationship with Ayako, even going to Ayako's home to buy her groceries on the weekends. Ayako treated him as a brother. However, right before I came to work for Orchid, Alan had left the Sakura and started his own business.

There are different versions of the reasons for Alan's departure. One staff member in Orchid told me that Alan was forced to leave because he was too arrogant and could not get along with Yang. He always thought it was him who made Ayako so popular, and looked down upon Yang and staff in Orchid. Alan could be viewed as a threat and a major stumbling block to Yang's domination of Ayako's production. However, another staff member told me that Alan quit merely because he wanted to start his own business to make more money. Whatever the reason, as the most trusted subordinate, and the only subordinate of Ushida, Alan's departure resulted in the weakening of Ushida's power in the two agencies.

After Alan left, Lily, one of Yang's most trusted people, replaced Alan as Ayako's manager. Lily's role has become very important because she has at least three important responsibilities, media manipulation, Ayako's dressing and makeup style, and business cooperation with clients. Thus Lily's responsibilities cover the most important parts of all the work related to Ayako: reproduction, representation and sales. In this way, Ushida's most trusted subordinate, Alan, was replaced with Yang's most trusted person, Lily. Basically, Lily listens to Ushida's directions as Ushida's subordinate. However, at the same time she also fulfills her responsibilities under Yang's instructions. Lily is frequently seen to go to Yang's office to get instructions about Ayako's issues since both the offices of Yang and Lily are on the third floor. Through his representative Lily, Yang has managed to gain control over Ayako's reproduction, representation and sales in China.

Besides Lily, other employees working near Ayako are also carefully selected from Orchid by Yang, instead of Ushida. Even if Ushida wanted to make Sakura more independent and autonomous, most of the staff working for Ayako, including Ayako's assistant, driver, bodyguard, interpreter (me in this case), recording staff, and others, are from Orchid. These staff also deal with Orchid's everyday work, exist as employees of Orchid and get their salary from Orchid. Taking my own work as an example, my routine work was to write promotional news or materials for all performers in Orchid, but when Sakura says that Ayako needs an interpreter for interviews or commercial activities, that takes priority over 
Orchid's everyday work. The advantage of such arrangements for Ushida is that Sakura can get free labor, and thus operate with low costs. Meanwhile, given that all the labor is distributed by Yang, Ushida's power inside the two agencies is further restricted.

Whether the arrangements of space and human resources are deliberate or not, as a result, they are beneficial for Yang to enhance his control over the reproduction and sales of Ayako, and realize his design and repositioning about Ayako. Although Ushida is authorized to wield great power over Ayako, and makes final decisions about Ayako's issues, his power is weakened in terms of the two agencies' operation. The spatial separation from other staff in Orchid resulted in his lack of communication with most staff in Orchid. All the staff working near Ushida are appointed by Yang. The isolation inside the two agencies results in difficulties of Ushida finding other promotion staff to replace the staff in Orchid or another promotion company to replace Orchid. New meanings deriving from Yang's repositioning strategies prevail over the meanings that Ushida aims to assign to Ayako in the process of promotion.

\section{Conclusion}

This paper examined how the two Chinese agencies intended to re-produce Ayako as a cultural product by assigning new meanings to her. The findings of this study reveal that the two Chinese agencies played a significant role in the "transformation" of Ayako as a global product in the local Chinese context, even though their operations are usually invisible to outsiders. The most important function of the two agencies is to make Ayako's image acceptable in China in their roles as Ayako's re-producer. Ayako's image as a Japanese AV actress needed to be altered primarily in order to adapt to the Chinese legal constraints around pornography. In order to remove her previous image as an AV actress, the two agencies asked Ayako to stop AV acting in Japan. Meanwhile, they sought to reposition Ayako's image as "an all-around star with acting and singing skills" and as "a cultural bridge between China and Japan". Through the new short movies and the mini concert backed by the two agencies, Ayako has been assigned new positive meanings, such as hard work, a model for young people pursuing dreams, the recognition of Chinese culture by Japanese people, and the advocacy of the friendship between China and Japan.

The findings challenge the two dominant paradigms: the homogenization paradigm and the creolization paradigm (Howes 1996). Scholars advocating the homogenization paradigm completely ignore (Schiller 1969; 
Hamelink 1983) the changes to the meanings of foreign products once they are consumed in a second (local) context. In contrast, scholars who emphasize the creativity of consumers (Liebes and Katz 1994, Watson 1997) risk attributing the emergence of all the new meanings to local consumers. This study shows that Ayako's image changed considerably after she migrated to China. The process of her migration does reveal the creativity of consumers because it is Ayako's amazing popularity among Chinese Internet users that led to the establishment of Ayako's two Chinese agencies. However, it was these two agencies that propelled further changes to her social meanings and made her a "politically correct" product. Therefore, it is inaccurate to attribute all the meanings of global products to foreign corporations, or to the creativity of local consumers. This paper argues that the crucial roles of intermediaries as re-producers and mediators between the global product and local groups should be taken into account when conceptualizing the migration of cultural goods.

Furthermore, the findings of the study suggest that the personal experiences of the key chief executive and power relations between different groups inside the intermediaries have a great impact on the transformation of Ayako's image in China. Business anthropologists study group behavior and organizational culture through qualitative data collection and analysis (Jordon 2010). In examining the roles of the local intermediaries, this paper does not treat the two Chinese companies as a monolith, but as a community consisting of different cultural groups with different interests. Ushida, the Japanese chief executive of Sakura, regards Ayako as a symbol of commercial value. He insisted that Ayako should be humorous in interviews and on Weibo to achieve high commercial value. Yang, the Chinese chief executive of Orchid and expert at producing celebrities, regards Ayako as one of his masterpieces and a means of self-actualization. Owing to his own ambition to make a name in history and the consideration of Chinese market, he repositions Ayako as a key figure who contributes to cultural exchanges between China and Japan in contemporary China. The reconstruction process of Ayako's image is accompanied with the power struggles Yang and Ushida. Thus this paper questions Nakano (2009)'s assumption that the local intermediaries are a coherent monolith in the process of re-producing foreign cultural products. Nakano's (2009) research allows us to pay attention to indispensable role of local intermediaries in the circulation of Japanese cultural products in Asia. However, it still has its limitations in the sense that it treated the local society as a coherent monolith.

Between the two chief executives, Yang's repositioning strategy has become widely shared and agreed upon within the two agencies and has 
become the prevailing guidance when Yang instructs employees in Ayako's promotion and publicity. New meanings deriving from Yang's repositioning strategy are essential for Ayako's transformation. The dominant status of Yang's repositioning strategy is not naturally obtained, but is guaranteed by the arrangements of space and human resources. As a result, there is a fundamental disjuncture between Ayako's previous image as a Japanese AV actress and her new image that Yang aims to construct. The disjuncture leads to dramatic "transformation" of the cultural meanings of the foreign product, instead of "partial" modification as Nakano (2009) and Wong and Yau's (2014) cases suggest. Participant observation "inside" the intermediaries is very necessary, although it is often complicated by the difficulties in obtaining approval. It is helpful to broaden our understanding of the functions of local intermediaries in the entire process of cross-cultural migration of cultural products and the impact of the struggles between different cultural groups over the meanings of cultural products.

\section{References}

Appadurai, A. (1996). Modernity at Large: Cultural Dimensions of Globalization. Minneapolis: University of Minnesota Press.

Chen, Z.K. (2009). 'Kongzi chuguo zhe wunian' [Confucius going aboard five years]. Renmin ribao haiwaiban, October 26.

Cochran, S. (2006). Chinese Medicine Men: Consumer Culture in China and Southeast Asia. Cambridge, Mass.: Harvard University Press.

Dale, K. \& Gibson B. (2008). The Spaces of Organisation and the Organisation of Space: Power, Identity and Materiality at Work. Basingstoke: Macmillan Palgrave.

Douglas, M. \& Barron I. (1979). The World of Goods: towards an Anthropology of Consumption. London: Routledge.

Du Gay, P.; Hall S., Janes, L., Madsen, A.K. \& Mackay, H. (1997). Doing Cultural Studies: the Story of the Sony Walkman. London: SAGE Publications.

Featherstone, M. \& Lash, S. (1995). "Globalization, Modernity and the Spatialization of Social Theory: An Introduction”. In M. Featherstone, S. Lash, R. Robertson (eds), Global Modernities (pp.1-25). London: SAGE Publications.

Goldstein-Gidoni, O. (2001). "The Making and Marking of the "Japanese" and the "Western" in Japanese Contemporary Material Culture'. Journal of Material Culture 6(1): pp. 67-90.

Hamelink, C.J. (1983). Cultural Autonomy in Global Communication. 
New York: Longmans.

Hannerz, U.I.F. (1996). Transnational Connections: Culture, People, Places. London: Routledge.

Hernes T. (2004). The Spatial Construction of Organization. Amsterdam: John Benjamins.

Howes, D. (1996). 'Introduction: Commodities and Cultural Borders'. In D. Howes (eds) Cross-cultural Consumption: Global Markets, Local Realities (pp. 1-18). London; New York: Routledge.

Jeffreys, E. \& Edwards, L. (2010). 'Celebrity/ China'. In E. Jeffreys \& L. Edwards (eds), Celebrity in China (pp. 1-20). Hong Kong: Hong Kong University Press.

Jordan, A.T. (2010). 'The Importance of Business Anthropology: Its Unique Contributions'. International Journal of Business Anthropology 1(1): pp. $15-25$.

Kidahashi, M. (1987). 'Dual organization: a study of a Japanese-owned firm in the United States', PhD diss., Columbia University.

Kornberger, M. \& Clegg, S. R. (2004). 'Bringing space back in: Organizing the generative building'. Organization Studies 25(7): pp. 1095-1114.

Liebes, T. \& Katz, E. (1994). The Export of Meaning: Cross-Cultural Readings of Dallas. Cambridge: Polity Press.

Love, J.F. (1986). McDonald's: Behind the Arches. Toronto, Ont.: Bantom Books.

March, R.M. (1992). Working for a Japanese Company: Insights into the Multicultural Workplace, Tokyo: Kodansya International.

Nakano, Y. (2009). Where there are Asians, there are Rice Cookers: How 'National' Went Global via Hong Kong. Hong Kong: Hong Kong University Press.

Peterson, R.A. (1994). 'Culture Studies through the Production Perspective: Progress and Prospects'. In Dinan C. (eds) The Sociology of Culture: Emerging Theoretical Perspectives (pp. 163-189). Cambridge: Blackwell.

Pieterse, J.N. (1995). 'Globalization as Hybridization'. In M. Featherstone, S. Lash, R. Robertson (eds), Global Modernities (pp. 45-68). London: SAGE Publications.

Ritzer, G. (2008). The McDonaldization of Society 5. Los Angles, Calif.: Pine Forge Press.

Schiller, H. (1969). Mass Communication and America Empire. New York: A. M. Kelley.

Tian, G. (2010). 'The Unique Contributions and the Unique Methodologies: A Concise Overview of the Applications of Business Anthropology'. 
International Journal of Business Anthropology 1(2): pp. 70-88.

Tomlinson, J. (1991). Cultural Imperialism: A Critical Introduction. London: Pinter Publishers.

Turner, G. (2004). Understanding Celebrity. London: SAGE Publications.

Walle, A.H. (2016). 'Ethnography: Naturalistic Research and Business Anthropology'. International Journal of Business Anthropology 6(1): pp. 27-46.

Watson, J.L. (1997). 'Introduction: Transnationalism, Localization, and Fast Foods in East Asia'. In J.L. Watson (eds), Golden Arches East: McDonald's in East Asia (pp. 1-38). Stanford, Calif.: Stanford University Press.

White, M. \& Trevor, M. (1983). Under Japanese Management: the Experience of British Workers. London: Heinemann.

Williams, R. (1961). The Long Revolution. London: Chatto \& Windus.

Wong, H.W. (1999). Japanese Bosses, Chinese Workers: Power and Control in a Hong Kong Megastore. Richmond: Curzon Press.

Wong, H.W. \& Yau H.Y. (2014). Japanese Adult Videos in Taiwan. Abingdon, Oxon: Routledge.

Yamaguchi, Y., Fujiwara, S. (1991). Jin R. J. trans. Zai Zhongguo de rizi: Li Xianglan, Wo de bansheng [RiKōran watakushi no hansei]. Hong Kong: Baixing wenhua shiye youxian gongsi.

Yang, Y.J. (2003). Cultural Nationalism in Contemporary China. London: Routledge.

\section{Acknowledgements}

This study is supported by the Louis Cha Fund for Chinese Studies and East/West Studies in the Faculty of Arts of the University of Hong Kong. 
